\title{
Ocular Morphology of the Japanese Special Natural Monument, the Amami Rabbit (Pentalagus furnessi), an Endemic Species in Amami Oshima
}

\section{Amagai $\mathbf{Y}^{1,2}$, Muko R², Matsuda $\mathbf{H}^{2,3}$ and Tanaka $\mathbf{A}^{2,4 *}$}

${ }^{1}$ Research Fellow of the Japan Society for the Promotion of Science

${ }^{2}$ Cooperative Major in Advanced Health Science, Graduate School of Bio-Applications and System Engineering, Tokyo University of Agriculture and Technology, Japan

${ }^{3}$ Laboratory of Veterinary Molecular Pathology and Therapeutics, Division of Animal Life Science, Tokyo University of Agriculture and Technology, Japan

Research Article

Volume 1 Issue 1

Received Date: April 26, 2018

Published Date: May 14, 2018

DOI: $10.23880 /$ izab-16000106

${ }^{4}$ Laboratory of Comparative Animal Medicine, Division of Animal Life Science, Tokyo University of Agriculture and Technology, Japan

*Corresponding author: Akane Tanaka, Professor, Tokyo University of Agriculture and Technology, Veterinary Medicine, Laboratory of Comparative Animal Medicine, 3-5-8, Saiwai-cho, Fuchu, Tokyo 183-8509, Japan, Tel: +81-42367-5925; Fax: +81-42-367-5916; Email: akane@cc.tuat.ac.jp

\section{Abstract}

Pentalagus furnessi (Amami rabbit) is an endemic rabbit only reside in the southern districts of Japan, and designated as a special natural monument in Japan. While conserving those animals is necessary, basic knowledge regarding their unique features remains unknown. In this study, we analyzed morphological and histological characteristics of the eyes which were obtained from an Amami rabbit died accidentally by a traffic accident. In the Amami rabbit, not tapetum-like structures but both pigmented and non-pigmented areas were observed. In addition, the non-pigmented area was much larger in the Amami rabbit compared to that in the laboratory rabbits (Oryctolagus cuniculus). In the histological analysis, layers of retina were corresponded to the standard vertebrate arrangement, though the sizes of cell nuclei in both the inner and outer granular layers were larger in the Amami rabbit compared to laboratory rabbits. While characteristics of eyes are highly conserved in the family Leporidae, smaller pigmented area in Amami rabbits may reflect the natural selection resulting from their nocturnal lifestyle. Understanding their characteristics further is necessary for conserving the unique and endangered hare in Japan.

Keywords: Amami rabbit; Eye; Pentalagus furnessi; Rabbit; Retina 


\section{International Journal of Zoology and Animal Biology}

Abbreviations: ONF: Ocular Nerve Fiber Layer; IP: Inner Plexiform Layer; IG: Inner Granular Layer; OP: Outer Plexiform Layer; OG: Outer Granular Layer; PL: Pigmented Layer.

\section{Introduction}

Pentalagus furnessi, also known as Amami rabbit, is a primitive and endemic rabbit, which is currently found only on two small islands in the southern districts of Japan: Amami Oshima and Tokuno-Shima islands [1]. The morphological features of the animal are different from those of common rabbits and hares; the ears and eyes are smaller, and their forelimb claws that they use to dig holes are larger (Figure 1a) [2,3]. Because the numbers of the animal are limited, they are designated as a special natural monument, and included as an endangered species (IB) in the Red Data List of the Environment Agency, Japan [4]. While their conservation is urgently required, basic information regarding their unique physiological and anatomical features as well as behaviors has remained unclear.

The main cause of death for these animals has been reported to be attacks by predators such as crotalid snakes, mongooses, feral dogs, and cats. In addition, traffic accidents, probably related to their nocturnal behavior, are attributed to the death of these animals [5,6]. In typical rabbit species, such as Oryctolagus cuniculus, the tapetum lucidum that plays an important role in light sensing in dark environments is absent [7]. Therefore, to verify whether the retinal structure in the Pentalagus furnessi is adapted for dim-light vision, we aimed to investigate the morphology of the eye, especially focusing on the gross and microscopic characters of the retina.

\section{Materials and Methods}

\section{Study Species}

Because Amami rabbits are designated as a special natural monument, we obtained the approval from the Environment Agency of Japan to collect eye samples. From a male Amami rabbit (presumably young adult) that accidentally died due to a traffic accident, we isolated eye balls and processed samples for histological analysis. The eyes isolated from laboratory rabbits (the Oryctolagus cuniculus; New Zealand White and Dutch rabbit) were purchased from Oriental Yeast Co., Ltd. (Tokyo, Japan).

\section{Histological Analysis}

The eyes were fixed in Davidson's solution $30 \%$ of a $37-40 \%$ solution of formaldehyde, 35\% ethanol, $10 \%$ glacial acetic acid, and distilled water) overnight at $4^{\circ} \mathrm{C}$, and then a horizontal incision was made to open the eye. The hematoxylin-eosin staining procedures were performed as described previously [8]. Photographs were taken using a BZ-9000 microscope (Keyence Corporation, Osaka, Japan).

\section{Results and Discussion}

Eyes from the Amami rabbit were enucleated from the animal four days after the accident. The retina was detached from the choroid, and both pigmented and nonpigmented areas were obvious, but no tapetum-like structure was observed (Figure 1b). Compared to the eyes from the Dutch and New Zealand White rabbit (Figures 1c and 1d), the non-pigmented area where capillaries were obvious was much larger in Pentalagus furnessi. Since the pigmented area plays a role in the shading of light, our observation suggests that this enlarged pigmented area is an adaptation of Amami rabbits that allows them to be active during dusk time in that environment. Horizontally running optic fibers are clearly recognized in Dutch rabbits, but not in Amami rabbits. Although it is difficult to understand the visual ability of Amami rabbits, the morphological differences observed in the study may be involved in the functional adaptation of their eyes to their unique lifestyle.

Next, histological analysis was performed. Layers of the retina, consisting of three neuronal cell layers (outer and inner granular layers and ganglion cell layer), inner segments, and a retinal pigment epithelial layer corresponding, in principle, to the standard vertebrate arrangement, were observed (Figures 1a and 2a). These retinal layers showed similar microscopic features in Pentalagus furnessi and the Dutch and New Zealand White rabbits (Figures $2 \mathrm{~b}$ and $\mathrm{c}$ ). Although the most retina was artificially detached from choroid in most area (Figures $2 \mathrm{a}$, left), the retinal structure from outer granular layer to the pigmented area was also similar to that of the Dutch rabbits (Figures 2a, right). The sizes of cell nuclei in the inner and outer granular layers of the Pentalagus furnessi were larger than that of the Oryctolagus cuniculus, suggesting the possibility of functional differences between the eyes of the Pentalagus furnessi and those of laboratory rabbits. 
(a)

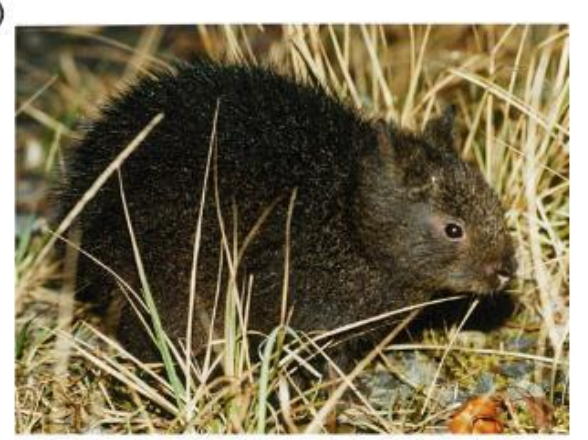

(b) Pentalagus furnessi
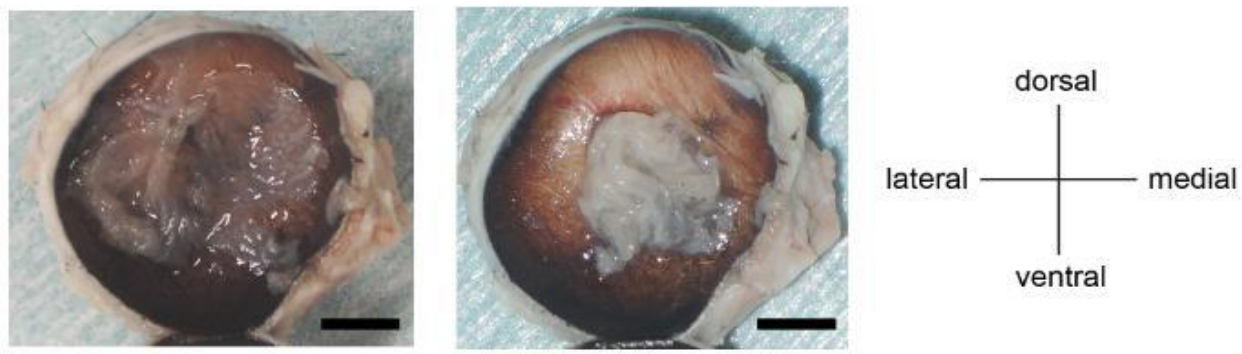

(c) Oryctolagus cuniculus (Dutch)
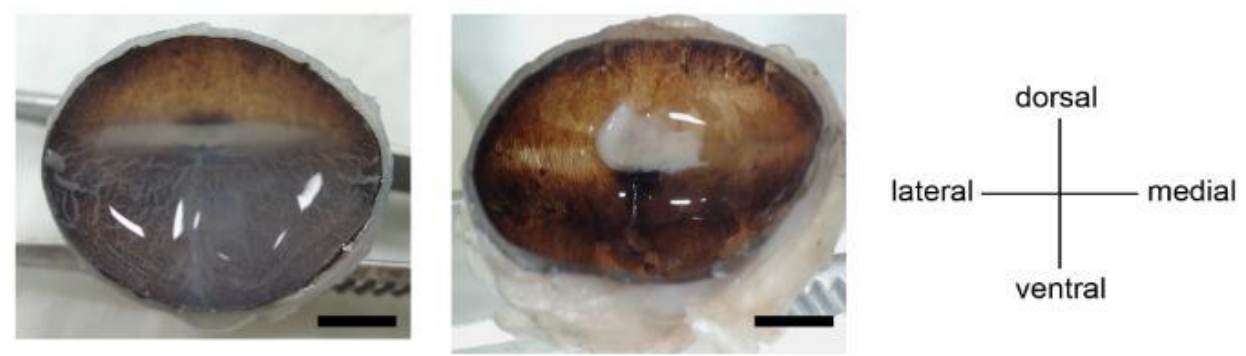

(d) Oryctolagus cuniculus (New Zealand White)
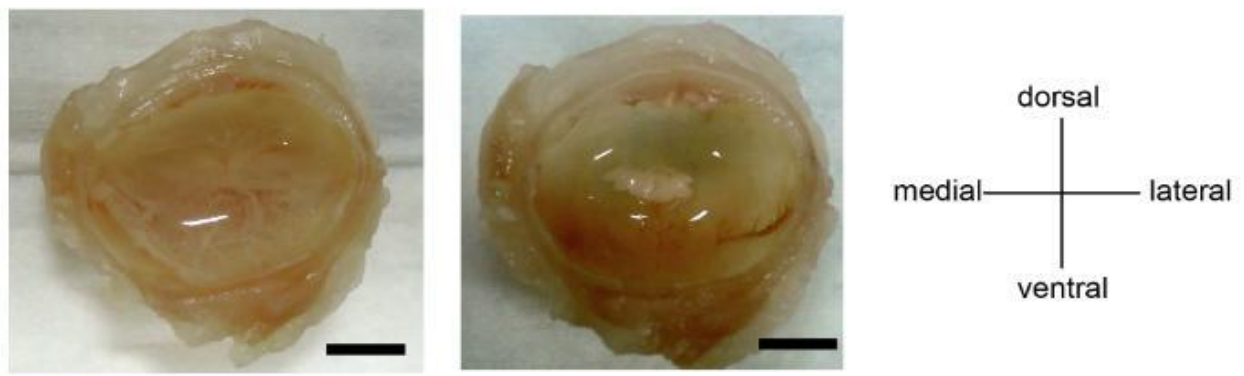

Figure 1a: Original photograph of a live Amami rabbit. Note that they have small ears and eyes. b-d: Anterior portion of the coronally sectioned eye of b. Amami rabbit, c: Dutch rabbit, and d: New Zealand White rabbit. Photographs with or without retina are shown separately. Scale Bar, $5 \mathrm{~mm}$. 
Our results indicate that the morphological and histological characteristics of eyes are conserved in the family Leporidae. Since the significance of tapetum-free anatomical features in rabbits is probably related to their crepuscular habituation, it is possible that Pentalagus furnessi may have originally behaved like other rabbits.
However, severe alteration of their living environments, including land development might force them to be active only at night. For activity in dim or dark environments, Amami rabbits with a small pigmented area in the retina may be naturally selected, evolving to form a species with nocturnal activity.

\section{(a) Pentalagus furnessi}

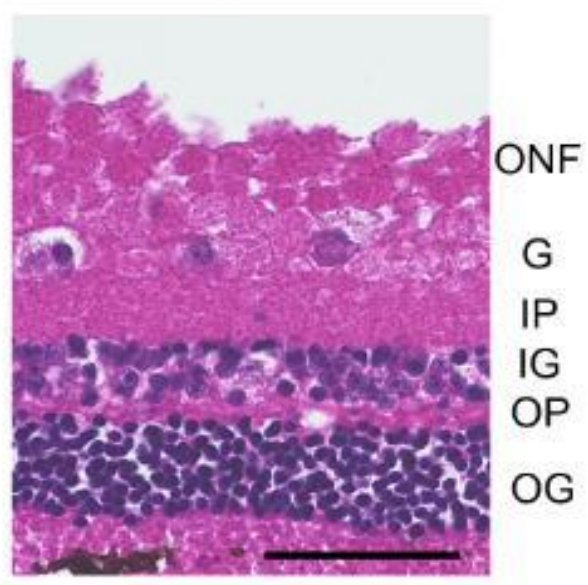

(b) Oryctolagus cuniculus (Dutch)

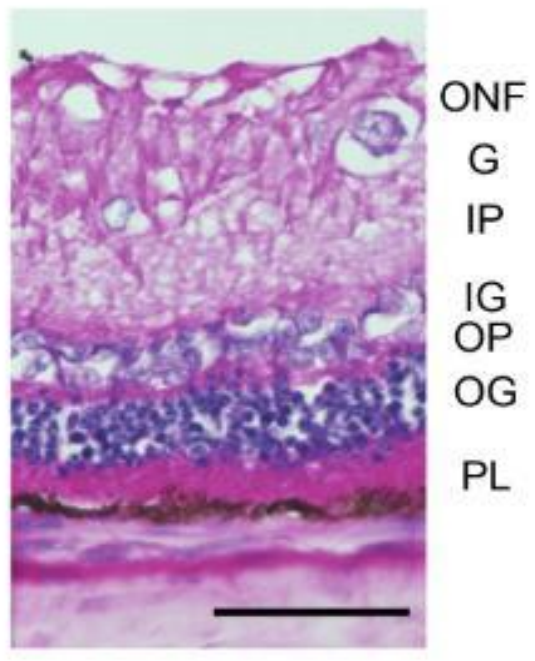

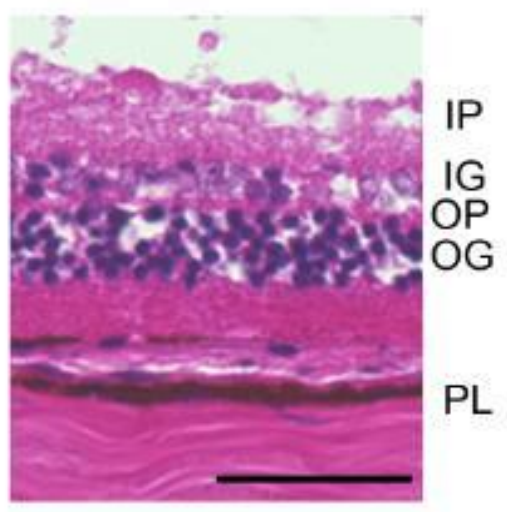

(c) Oryctolagus cuniculus (New Zealand White)

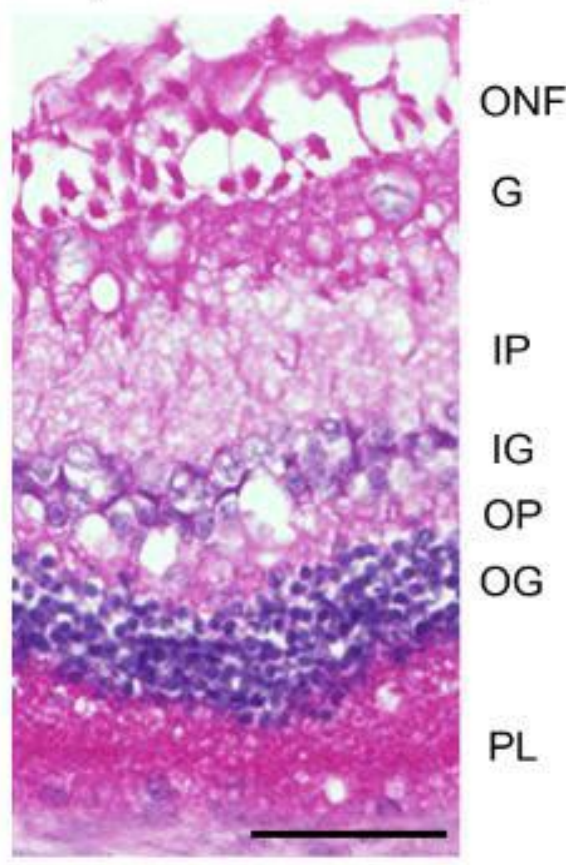


Figure 2: Histological section of the retina of a: Amami rabbit, b: Dutch rabbit, and c: New Zealand White rabbit. Because most retina was detached in the section of Amami rabbit (left), small area that can observe outer granular layer and pigmented layer was also shown (right). Scale Bar, $50 \mu \mathrm{m}$. ONF, ocular nerve fiber layer; G, ganglion cell layer; IP, inner plexiform layer; IG, inner granular layer; OP, outer plexiform layer; OG, outer granular layer; PL, pigmented layer.

\section{Conclusion}

Morphological and histological characteristics of the eyes obtained from the Amami rabbit were highly conserved in the family Leporidae, lacking tapetum-like structures while the non-pigmented area was much larger in the Amami rabbit. Pentalagus furnessi in Amami Oshima and Tokuno-Shima islands are very unique wild rabbits, and they require intensive care for further conservation as a world treasure.

\section{Acknowledgement}

We appreciate Drs. Chizuru Iwamoto and Yuna Kimoto (conservation officer and conservation officer assistant in Amami Wildlife Center, respectively, Yamato village, Kagoshima, Japan) for their kind support and providing a post-mortem sample of the Pentalagus furnessi. We also express our gratitude to Mr. Makoto Nobata and Ms. Rie Hayakawa (Yamato village office, Kagoshima, Japan) for providing original photos of wild Amami rabbits. Moreover, we are grateful to Dr. Kaoru Karasawa and Ms. Mayumi Shibayama (Tokyo University of Agriculture and Technology, Tokyo, Japan) as well as Mr. Tetsuyoshi Hamasaki (Gray Art, Co., Ltd., Tokyo, Japan) for their supports. Earnest cooperation and support obtained from staff in Yamato village office are greatly appreciated.

\section{References}

1. Robinson TJ, Yang F, Harrison WR (2002) Chromosome painting refines the history of genome evolution in hares and rabbits (order lagomorpha). Cytogenet Genome Res 96 (1-4): 223-227.

2. Yamada F, Takaki M, Suzuki H (2002) Molecular phylogeny of Japanese Leporidae, the amami rabbit Pentalagus furnessi, the Japanese hare lepusbrachyurus, and the mountain hare lepustimidus, inferred from mitochondrial DNA sequences. Genes Genet Syst 77(2): 107-116.

3. Yamada F, Cervantes FA (2005) Pentalagus furnessi. Mammalian Species 782: 1-5.

4. Ministry of the Environment (2013) Red list and red data book for mammals in Japan. Ministry of the Environment, Tokyo, Japan.

5. Sugiura K, Sato S, Yamada F, Abe S, Handa Y, Hirakawa H (2000) Distribution and abundance of the amami rabbit Pentalagus furnessi in the amami and tokuno islands, Japan. Oryx 34 (3): 198-206.

6. Ministry of the Environment (2015) The wildlife in Japan. Ministry of the Environment, Tokyo, Japan.

7. Gelatt KN, Gilger BC, Kern TJ (2013) Veterinary Ophthalmology, $5^{\text {th }}$ (Edn.), Wiley, ISBN 978-0-47096040-0.

8. Tanaka A, Muto S, Jung K, Itai A, Matsuda H (2007) Topical application with a new NF-kappaB inhibitor improves atopic dermatitis in NC/Nga Tnd mice. J Invest Dermatol 127(4): 855-863. 